\title{
Hubungan Kualitas Air dengan Pertumbuhan Semai Rhizophora mucronata Lamk. Pada Periode Pengamatan yang Berbeda
}

\section{Relationship Water Quality and Seedling Growth of Rhizophora mucronata Lamk. In Different Observation Periods}

\author{
Solikhah $^{1}$, Endah Dwi Hastuti ${ }^{2} *$, Rini Budihastuti ${ }^{2}$ \\ ${ }^{1}$ Mahasiswa Program Studi Biologi, Departemen Biologi, Fakultas Sains dan Matematika \\ ${ }^{2}$ Departemen Biologi, Fakultas Sains dan Matematika, Universitas Diponegoro \\ Jalan Prof. H.Soedarto, SH, Tembalang, Semarang 50275 \\ *Email : endah_pdil@yahoo.com
}

Diterima 30 Juli 2018 / Disetujui 29 September 2018

\begin{abstract}
ABSTRAK
Pengelolaan kawasan tambak dapat dilihat dari peran mangrove dalam pengendalian kualitas lingkungan tambak. Pengelolaan ekosistem mangrove dapat dilakukan dengan polikultur atau wanamina (silvofishery). Penelitian ini bertujuan untuk mengetahui hubungan kualitas air (suhu, kekeruhan, salinitas, $\mathrm{pH}$, dan DO) terhadap pertumbuhan semai Rhizophora mucronata Lamk. pada periode pengamatan yang berbeda di saluran tambak wanamina Semai mangrove sangat rentan terhadap perubahan lingkungan, sehingga kemampuan adaptasi terhadap lingkungan tumbuhnya menentukan keberhasilan pertumbuhan. Metode yang digunakan dalam penelitian ini yaitu Rancangan Acak Lengkap (RAL) dengan perlakuan periode pengamatan. Analisis data yang digunakan berupa analisis varians (ANOVA) satu faktor (periode pengamatan) dengan 6 perlakuan yaitu periode pengamatan I, II, III, IV, V , dan VI serta analisis regresi linear berganda untuk mengetahui hubungan kualitas lingkungan dengan pertumbuhan semai. Analisis data menunjukkan bahwa tingkat pertumbuhan daun rendah, pertumbuhan jumlah cabang belum ditemukan, diameter batang dan tinggi tanaman mengalami pertumbuhan. Periode pengamatan berpengaruh terhadap kualitas air. Kualitas air yg berpengaruh nyata yaitu suhu, kekeruhan dan salinitas. Kekeruhan dan suhu merupakan parameter kualitas air yang memiliki hubungan paling erat dengan pertumbuhan semai Rhizophora mucronata.
\end{abstract}

\section{Kata kunci: Rhizophora mucronata, kualitas lingkungan Pertumbuhan Rhizophora}

\begin{abstract}
Management of pond area can be seen from the role of mangrove in controlling the quality of pond environment. Management of mangrove ecosystem can be done with polikultur or wanamina (silvofishery). This study aims to determine the relationship of water quality (temperature, turbidity, salinity, $\mathrm{pH}$, and DO) to the growth of Rhizophora mucronata Lamk seedling. in different observation periods in the wan mesh channel of Semai mangroves are very susceptible to environmental changes, so the ability to adapt to the growing environment determines the success of growth. The method used in this research is Completely Randomized Design (RAL) with treatment of observation period. Analyze the data used in the form of analysis of variance (ANOVA) one factor (observation period) with 6 treatment that is observation period I, II, III, IV, V, and VI and multiple linear regression analysis to know relation of environmental quality with growth of seedlings. The data analysis showed that the leaf growth rate was low, the growth of the number of branches had not yet been found, the stem diameter and the height of the plant were growing. Observation period has an effect on water quality. The quality of water that has real effect is temperature, turbidity and salinity. Turbidity and temperature are parameters of water quality that have the most close relationship with the growth of Rhizophora mucronata seedlings.
\end{abstract}

Keywords: Rhizophora mucronata, environmental quality, Rhizophora growth 


\section{PENDAHULUAN}

Kerusakan yang terjadi di kawasan pesisir pantai, dapat mempengaruhi lingkungan tambak disekitar pantai, sehingga perlu di upayakan perbaikan kualitas lingkungan pesisir pantai dengan cara penanaman semai mangrove pada tambak. Menurut Walters et al. (2008) pengelolaan mangrove diperlukan untuk menjaga kelangsungan pemanfaatan sumberdaya di wilayah pesisir. Dengan terjaganya ekosistem mangrove di wilayah pesisir. Dengan demikian kelangsungan pemanfaatan sumberdaya pesisir dapat dipertahankan dan dilestarikan.

Pengelolaan kawasan tambak dapat dilihat dari peran mangrove dalam pengendalian kualitas lingkungan tambak. Menurut Dahuri (2012), pengelolaan ekosistem mangrove dapat dilakukan dengan polikultur atau wanamina (silvofishery). Menurut Raswin, (2003), perubahan kualitas lingkungan yang terdapat pada lingkungan pesisir serta lingkungan tambak sedikit banyak mempengaruhi kualitas air yang secara langsung mempengaruhi pertumbuhan vegetasi mangrove. Wantasen (2013) menyatakan, kualitas perairan perlu diteliti karena sangat penting bagi kelangsungan proses-proses ekologi (siklus nutrien, stabilitas lingkungan, dan sistem penyangga kehidupan) dan pertumbuhan vegetasi mangrove. Berdasarkan uraian diatas, maka perlu dilakukan penelitian untuk mengetahui hubungan kualitas air dengan pertumbuhan mangrove pada periode pengamatan yang berbeda.

\section{METODE PENELITIAN}

Penelitian dilakukan selama 3 bulan ( Maret sampai Juni 2015 ). Penelitian di lakukan di Desa Mangunharjo Kecamatan Tugu, kota semarang. Pengamatan dilakukan secara berkala dengan periode pengamatan setiap 2 minggu (15 hari). Alat yang digunakan pada penelitian ini antara lain : wather quality checker, $\mathrm{DO}$ meter, $\mathrm{pH}$ meter, jangka sorong, meteran jahit, kamera dan alat tulis. Bahan yang digunakan antara lain: semai mangrove Rhizophora mucronata dan Avicenia yang berumur 3 bulan,bamboo, plastic, dan tali raffia.

\section{Pembuatan Petak Tambak dan Saluran}

Tambak yang digunakan dalam penelitian ini memiliki susunan seri yang berurutan dari satu petak tambak dengan petak tambak yang lain. Saluran tambak dibuat disamping kolam tambak yang memiliki luas $25 \mathrm{~m}^{2}$. Panjang saluran berukuran 5 meter dengan lebar $3 \mathrm{~m}$, antara tambak dan saluran dibatasi dengan plastik, kecuali pada pintu masuk air (inlet) dan pintu keluar air (outlet) saluran tambak yang berukuran $1 \mathrm{~m}$.

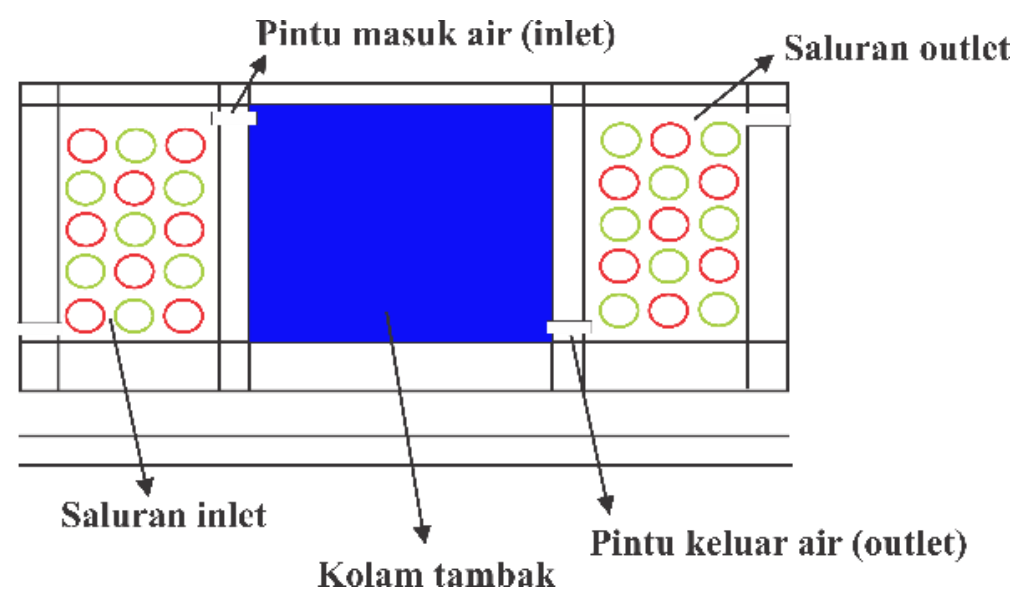

Gambar 1. Pola susunan tambak pada penelitian 


\section{Seleksi Semai}

Semai yang dipilih yaitu semai yang berumur 3 bulan tidak layu (berwarna hijau) dan memiliki ukuran tinggi rata-rata $30-40 \mathrm{~cm}$. Semai diberi alat bantu tegakan (batang bambu), antarsemai diberi jarak 1 meter, kemudian semai dan batang bambu di ikat dengan tali rafia. Semai yang ditanam berjumlah 15 semai meliputi 8 semai Rhizophora mucronata Lamk. dan 7 semai Avicennia marina (selang seling).

\section{Teknik Pengumpulan Data}

Data diambil setiap 2 minggu sekali. Pada pengamatan pertumbuhan semai Rhizophora mucronata, parameter yang diamati yaitu jumlah daun, jumlah cabang, diameter batang, dan tinggi tanaman. Suhu, kekeruhan, salinitas, $\mathrm{pH}$, oksigen terlarut (DO) air pada saluran tambak wanamina diukur dengam menggunakan water quality checker,nilai suhu ditunjukkan pada layar water quality checker.

\section{Rancangan Penelitian}

Penelitian ini dirancang untuk menganalisis hubungan fluktuasi kualitas air terhadap pertumbuhan semai Rhizophora mucronata Lamk. pada komunitas campuran. Rancangan penelitian ini menggunakan Rancangan Acak Lengkap (RAL), dengan pengamatan sebanyak enam perlakuan yaitu periode pengamatan.

\section{Analisis Data}

Analisis data dilakukan dengan uji analisis varians (ANOVA) untuk parameter pertumbuhan dan parameter kualitas air agar terlihat adanya beda nyata pada periode pengamatan yang berbeda. Analisis data selanjutnya yaitu uji regresi linear berganda yang digunakan untuk mengetahui adanya hubungan kualitas air dengan pertumbuhan semai Rhizophora mucronata.

\section{HASIL DAN PEMBAHASAN}

\section{Pertumbuhan Semai Rhizophora mucronata}

Berdasarkan uji normalitas dan homogenitas, data tidak berdistribusi normal dikarenakan nilai $\mathrm{p}<0,05$. Jumlah daun, diameter batang, jumlah cabang, dan tinggi tanaman tidak memiliki pola seragam meskipun telah dilakukan transformasi data. Berdasarkan hal tersebut, data tidak bisa dilakukan uji lanjut dengan ANOVA karena data tidak berdistribusi normal dan tidak memiliki pola yang seragam. Cuaca dan iklim pada daerah penelitian sudah mulai memasuki musim kemarau. Kemarau menyebabkan cuaca terik dan suhu udara meningkat. Berdasarkan hasil pengamatan, suhu air pada periode tersebut mencapai $30^{\circ}-33^{\circ} \mathrm{C}$. Hal ini menyebabkan tanaman mengalami stres pada awal pertumbuhan. Menurut Pahalawattaarachchi (1998) dalam Jayakody, et al (2008), kadar salinitas yang tinggi selama musim kemarau dengan tingkat curah hujan rendah menyebabkan mangrove mengalami stres dan menyebabkan daun menjadi gugur.

Pertumbuhan diameter batang merupakan pertumbuhan sekunder yang disebabkan oleh adanya jaringan kambium, yaitu jaringan yang mengakibatkan batang bertambah besar (Triharso, 2004). Pertumbuhan diameter berlangsung apabila keperluan hasil fotosintesis untuk respirasi, penggantian daun, pertumbuhan akar dan tinggi telah terpenuhi (Latifah, 2004).

Menurut Kahangama (2007) dalam Jayakody, et al (2008), mangrove yang mengalami pertumbuhan paling tinggi biasanya mangrove yang tumbuh dekat dengan daerah yang frekuensi genangan air estuarine lebih sering dibandingkan dengan air yang menuju daratan.

\section{Kualitas Air Tambak Wanamina pada Struktur Komunitas Campuran}

Berdasarkan uji normalitas dan homogenitas, semua parameter kualitas air memiliki pola distribusi yang normal serta data yang seragam $(p>0,05)$. Sehingga semua parameter kualitas air dapat dilakukan uji analisis varians (ANOVA).

Berdasarkan gambar 5 tersebut, suhu yang terdapat pada saluran tambak wanamina merupakan suhu yang baik untuk mendukung 
pertumbuhan Rhizophora mucronata. Menurut Kusmana (1995) dalam Iman (2014), Mangrove tumbuh subur pada daerah tropis dengan suhu lebih dari $20^{\circ} \mathrm{C}$ dengan kisaran perubahan suhu rata-rata kurang dari $50^{\circ} \mathrm{C}$. Suhu berperan penting dalam proses fisiologis (fotosintesis dan respirasi).

Berdasarkan gambar 6, kekeruhan cenderung menurun (semakin cerah). Odum (1971) dalam Raharjo (2003) menyatakan bahwa kecerahan perairan merupakan faktor fisika yang menentukan jauhnya penetrasi cahaya yang masuk kedalam perairan yang dapat mendukung proses fotosisntesis tanaman. Semakin cerah suatu perairan maka proses fotosintesis tanaman akan lebih baik, sehingga pertumbuhan tanaman akan lebih optimal.

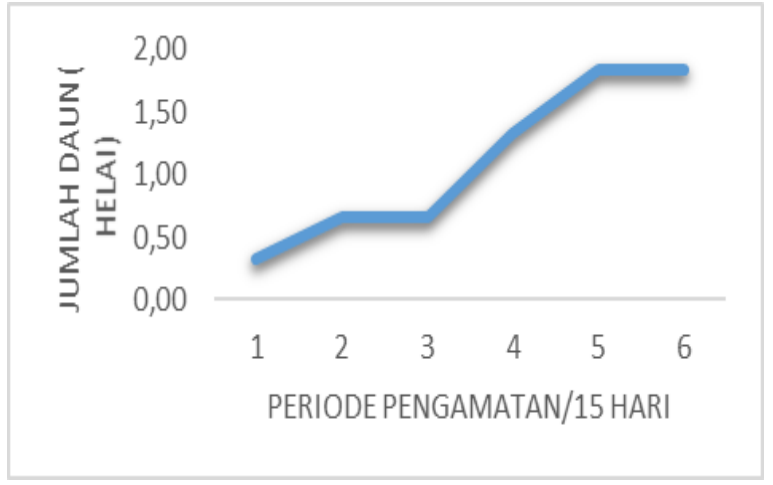

Gambar 2. Pertumbuhan Jumlah Daun Semai Rhizophora mucronata pada Periode Pengamatan yang Berbeda

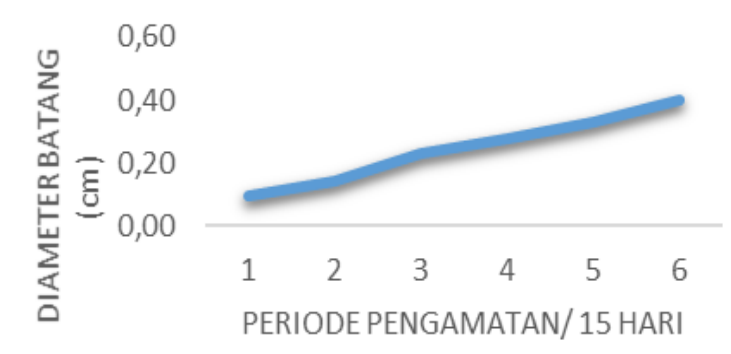

Gambar 3. Pertumbuhan Diameter Batang Semai Rhizophora mucronata pada Periode Pengamatan yang Berbeda

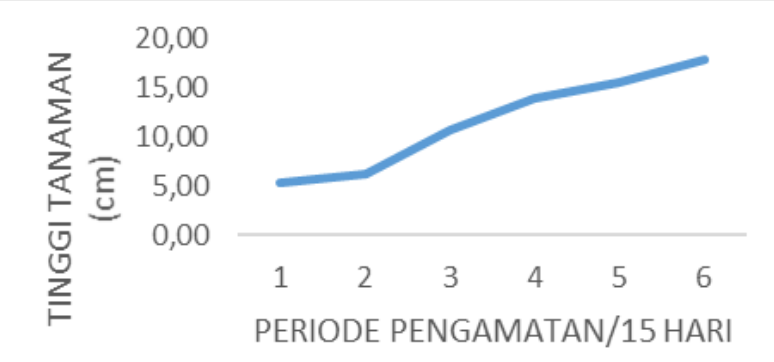

Gambar 4. Pertumbuhan Tinggi Semai Rhizophora mucronata pada Periode Pengamatan yang Berbeda 


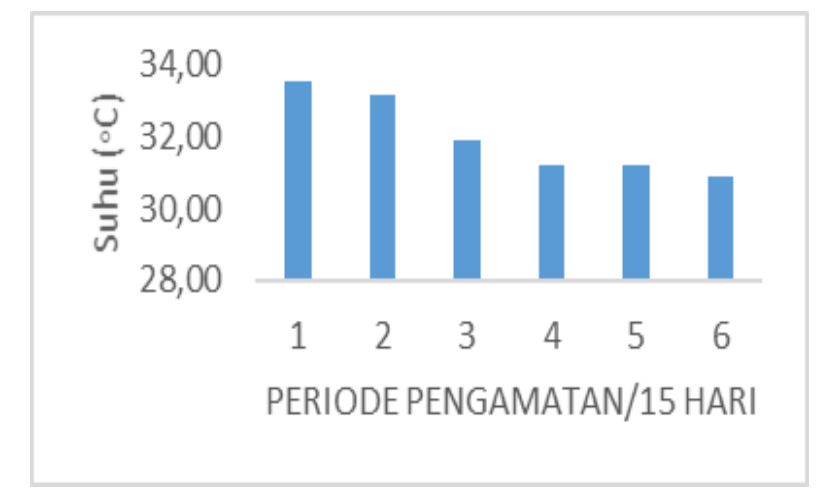

Gambar 5. Suhu Air Saluran Tambak Wanamina pada Periode Pengamatan yang Berbeda

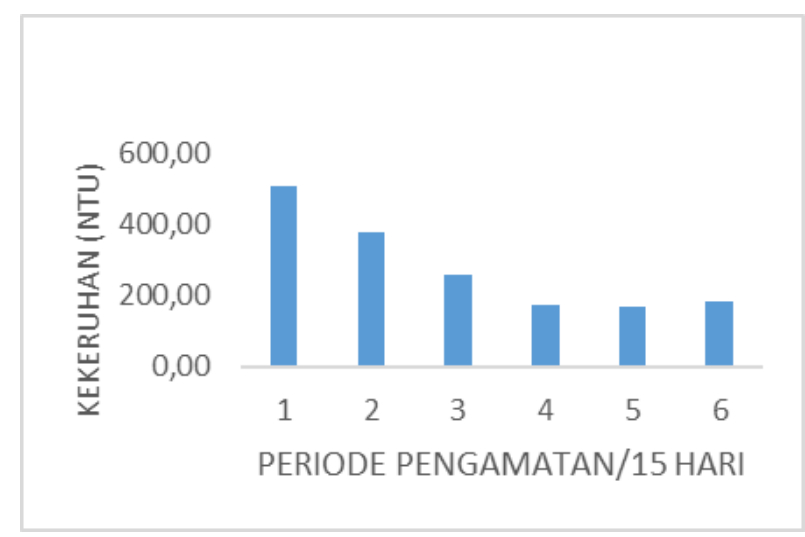

Gambar 6. Kekeruhan Air Saluran Tambak Wanamina pada Periode Pengamatan yang Berbeda

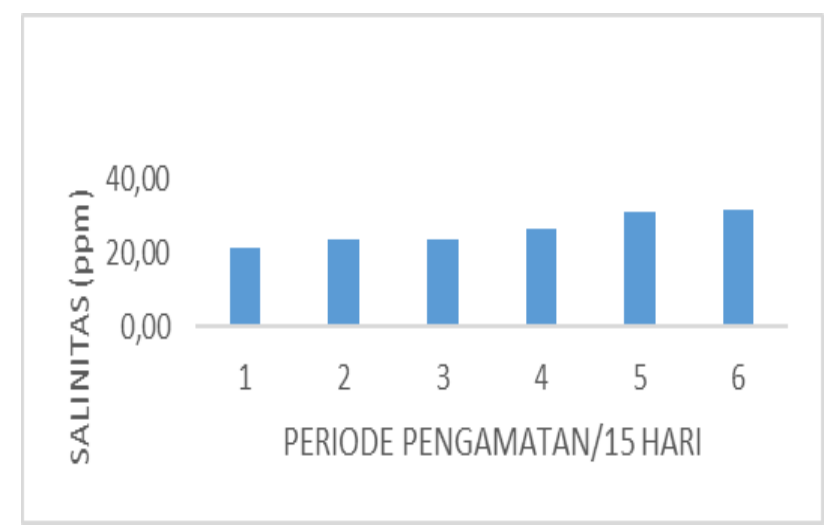

Gambar 7. Salinitas Air Saluran Tambak Wanamina pada Periode Pengamatan yang Berbeda

Gambar 7 , menunjukkan bahwa salinitas tertinggi terdapat pada periode VI yaitu sebesar $31,58 \mathrm{ppm}$, sedangkan salinitas terendah terdapat pada periode I yaitu sebesar 21,28 ppm. Menurut Kusmana (1995) dalam Iman (2014), salinitas optimum yang dibutuhkan mangrove untuk tumbuh berkisar antara 10-30 \%o. Sehingga salinitas saluran tambak wanamina yang ditunjukkan pada Gambar 4.6 cocok untuk pertumbuhan mangrove.

Menurut Sadat (2004) ekosistem mangrove dapat tumbuh dengan baik di perairan yang memiliki kisaran $\mathrm{pH}$ antara 6,0 - 9,0 . Sehingga $\mathrm{pH}$ saluran tambak wanamina yang ditunjukkan pada Gambar 4.6 cocok untuk pertumbuhan mangrove. 


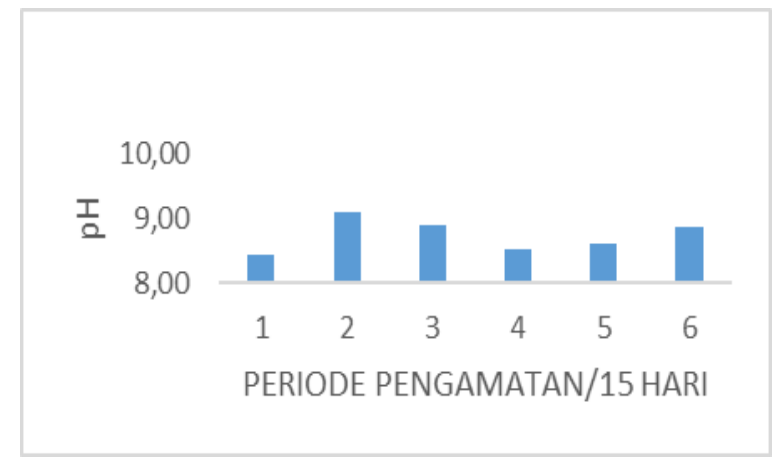

Gambar 8. pH Air Saluran Tambak Wanamina pada Periode Pengamatan yang Berbeda

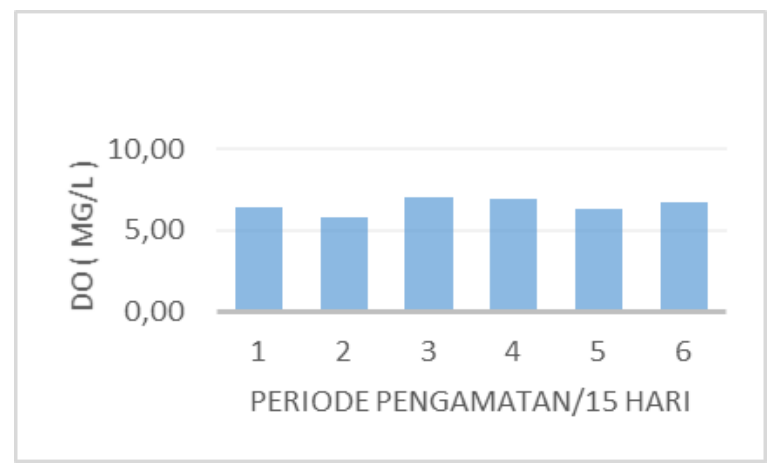

Gambar 9. DO Air Saluran Tambak Wanamina pada Periode Pengamatan yang Berbeda

Menurut Simanjuntak (2009), Kadar oksigen terlarut antara lain disebabkan pelepasan oksigen ke udara, aliran air tanah ke dalam perairan, adanya zat besi, reduksi yang disebabkan oleh desakan gas lainnya dalam air, respirasi biota dan dekomposisi bahan organik.

\section{Hubungan Kualitas Air dengan Pertumbuhan Semai Rhizophora mucronata pada periode pengematan yang berbeda di saluran tambak wanamina}

Hubungan kualitas air dengan pertumbuhan semai Rhizophora mucronata dapat diketahui dengan uji regresi dengan menggunakan software SPSS 23. Data kualitas air yang digunakan yaitu suhu, kekeruhan, salinitas, $\mathrm{pH}$, dan DO, sedangkan data pertumbuhan yang digunakan yaitu tinggi tanaman, diameter batang dan jumlah daun.

Tabel 1 Pengaruh Kualitas Air terhadap Pertumbuhan Tinggi Semai Rhizophora mucronata

\begin{tabular}{llccc}
\hline No & Parameter & Persamaan & $\mathbf{R}^{\mathbf{2}}$ & Signifikansi \\
\hline $\mathbf{1}$ & Kekeruhan & $\mathrm{Y}=16,045+0,044 \mathrm{X}$ & 0,279 & 0,079 \\
$\mathbf{2}$ & Suhu & $\mathrm{Y}=-122,627+4,717 \mathrm{X}$ & 0,247 & 0,146 \\
$\mathbf{3}$ & DO & $\mathrm{Y}=41,028+(-1,942) \mathrm{X}$ & 0,106 & 0,537 \\
$\mathbf{4}$ & Salinitas & $\mathrm{Y}=50,999+(-0,867) \mathrm{X}$ & 0,132 & 0,442 \\
$\mathbf{5}$ & pH & $\mathrm{Y}=40,470+7,872 \mathrm{X}$ & 0,207 & 0,225 \\
\hline
\end{tabular}

Berdasarkan Tabel 1, parameter kualitas air yang memberikan pengaruh signifikan terhadap pertumbuhan tinggi semai Rhizophora mucronata kekeruhan dan suhu. $\mathrm{R}^{2}$ lebih besar dibandingkan 
parameter yang lain. Kekeruhan memberikan pengaruh kuat terhadap pertumbuhan tinggi semai Rhizophora mucronata. Parameter lain yaitu suhu, salinitas, $\mathrm{pH}$ dan DO pengaruhnya tidak sekuat kekeruhan terhadap pertumbuhan tinggi semai Rhizophora mucronata ( $\mathrm{p}>0,1$ ). Kekeruhan dapat mempengaruhi kehidupan mangrove karena dapat menghalangi penetrasi cahaya yang dibutuhkan oleh mangrove untuk berfotosintesis. Kekeruhan terjadi karena terdapat sedimen yang terendapkan di bawah air. Tingkat kekeruhan yang relative tinggi bisa berpengaruh negatif bagi pertumbuhan semai,karena semai Rhizophora mucronata belum memiliki akar yang berkembang sehingga akar sulit untuk memperoleh oksigen untuk bernafas.

Berdasarkan analisis data, selain kekeruhan suhu memberikan pengaruh signifikan terhadap pertumbuhan tinggi semai Rhizophora mucronata. Suhu berperan cukup penting dalam proses fisiologis, yaitu fotosintesis dan respirasi. Berdasarkan data yang diperoleh di lapangan, suhu berkisar dari $30-33^{\circ} \mathrm{C}$. Muhamaze (2008) dalam Saru (2009) menyatakan bahwa temperatur ratarata yang mendukung pertumbuhan mangrove maksimal sebesar $32^{\circ} \mathrm{C}$ pada siang hari dan minimal $23^{\circ} \mathrm{C}$ pada malam hari. Manurut Gillman et al (2008), kisaran suhu optimal bagi fotosintesis mangrove yaitu $28-32^{\circ} \mathrm{C}$ sedangkan suhu $>38^{\circ} \mathrm{C}$ mengakibatkan terhentinya proses fotosintesis pada daun. Adanya kenaikan suhu berdampak pada peningkatan metabolisme dan laju resprirasi, jika peningkatan suhu terjadi melebihi ambang batas toleransinya

\section{KESIMPULAN}

Pertumbuhan Rhizophora mucronata pada periode pengamatan mengalami peningkat seiring dengan waktu pengamatan yaitu sebagai berikut: tingkat pertumbuhan daun rendah, pertumbuhan jumlah cabang belum ditemukan, diameter batang dan tinggi tanaman mengalami pertumbuhan Periode pengamatan berpengaruh terhadap kualitas air. Kualitas air yg berpengaruh nyata yaitu suhu, kekeruhan dan salinitas Kualitas air berhubungan dengan pertumbuhan tinggi tanaman. Kekeruhan dan suhu menunjukan pengaruh paling kuat dibandingkan salinitas, $\mathrm{pH}$, dan DO.

\section{DAFTAR PUSTAKA}

Dahuri,R. 2012. Mengembalikan Kembali Perekonomian Indonesia Melalui Sektor Perikanan dan Kelautan. LISPI : Jakarta.

Duke, N.C. 2006. Rhizophora apiculata, $R$. mucronata, $R$. Stylosa, $R$. annamalai, $R$. lamarckii (Indo-West Pacific stilt mangrove). Indo-West Pasific Rhizophora Species.

Iman, Akhzan Nur. 2014. Kesesuaian Lahan untuk Perencanaan Rehabilitasi Mangrove dengan Pendekatan Analisis Elevasi di Kuri Caddi, Kabupaten Maros. Skripsi. Universitas Hasanuddin.

Gilman E.L., Ellison J., Duke N.C., Field C. 2008. Threats to Mangroves from Climate Change and Adaptation Options: A Review. Aquatic Botany 89: 237-250

Jayakody, J.M.A.L., M.D. Amarasinghe., V. Pahalawattaarachchi., and K.H W.L De Silva. 2008. Vegetation Structure and Potential Gross Primary Productivity of Mangroves at Kadolkele in Meegamuwa (Negombo) Estuary, Sri Lanka. (13): 95108.

Kusmana, C., S. Wilarso, I. Hilwan, P. Pamoengkas, C. Wibowo, T. Tiryana, A. Triswanto, Yunasfi, Hamzah, 2003. Teknik Rehabilitasi Mangrove. Fakultas Kehutanan IPB. Bogor. 177 Hal.

Latifah, S. 2004. Analisis Vegetasi Hutan Alam. EUSU Repository. Medan.

Raswin, M. (2003). Pembesaran ikan bandeng. Modul: Pengelolaan air tambak. Direktorat Jakarta: Pendidikan Dasar dan Menengah, Kementerian Pendidikan Nasional.

Sadat, A. 2004. Kondisi Ekosistem Mangrove Berdasarkan Indikator Kualitas Lingkungan ean Pengukuran Morfometrik Daun di Way Penet Kabupaten Lampung Timur Provinsi Lampung. Skripsi. 
Fakultas Perikanan dan IlmuKelautan Institut Pertanian Bogor. Bogor. 55 Hal.

Simanjuntak, Marojahan. 2009. Hubungan Faktor Lingkungan Kimia, Fisika terhadap Distribusi Plankton di Perairan Belitung Timur, Bangka Belitung. XI (1): 3145.

Triharso. 2004. Dasar-Dasar Perlindungan Tanaman. Universitas Gadjah Mada. Yogyakarta.

Walters, B.B., P. Ronnback, J.M. Kovacs, B. Crona, S.A. Hussain, R. Badola, J.H. Primavera, E. Barbier, F. Dahdouh Guebas, 2008, Ethnobiology, Socio Economics and Management of Mangrove Forests: A review, Aquatic Botany 89: 220 $-236$ 